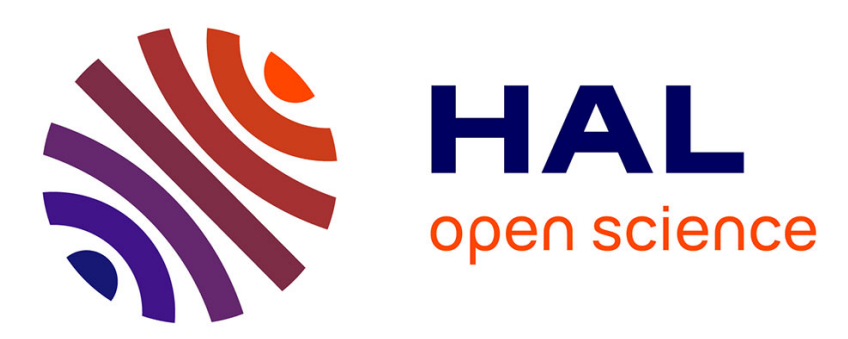

\title{
Does Productivity Decline after Promotion? The Case of French Academia
}

\author{
Mareva Sabatier
}

\section{To cite this version:}

Mareva Sabatier. Does Productivity Decline after Promotion? The Case of French Academia. Oxford Bulletin of Economics and Statistics, 2012, 74 (6), pp.886-902. hal-00825985

\section{HAL Id: hal-00825985 \\ https://hal.science/hal-00825985}

Submitted on 25 May 2013

HAL is a multi-disciplinary open access archive for the deposit and dissemination of scientific research documents, whether they are published or not. The documents may come from teaching and research institutions in France or abroad, or from public or private research centers.
L'archive ouverte pluridisciplinaire HAL, est destinée au dépôt et à la diffusion de documents scientifiques de niveau recherche, publiés ou non, émanant des établissements d'enseignement et de recherche français ou étrangers, des laboratoires publics ou privés. 


\title{
Does productivity decline after promotion? The case of French academia
}

\author{
MAREVA SABATIER ${ }^{1}$ \\ Université de Savoie - IAE Savoie Mont-Blanc - IREGE, BP 80439, 74944 Annecy-le- \\ Vieux Cedex - France \\ (e-mail: mareva.sabatier@univ-savoie.fr)
}

Abstract:

The present research examined the effect of promotion decisions on ex-post productivity in French academia. As, once promotion decisions are known, most external incentives vanish for promoted candidates, their productivity was expected to decrease. This hypothesis was tested by using an original dataset and matching methods to evaluate the impact of promotion on publication scores. The robustness of the matching estimates was tested using sensitivity analysis. The results clearly show that the removal of extrinsic incentives following promotion does not lead to a fall in productivity in French academia.

JEL Code: M51, J24, J45

Keywords: promotions, extrinsic and intrinsic incentives, academic career

\footnotetext{
${ }^{1}$ Acknowledgements: I would like to thank Anna Risch for her invaluable help in managing the dataset. I also thank Stephen Bazen and everyone who took part in the Careers in Academia research project for their helpful comments, in particular Christine Musselin and Frédérique Pigeyre. This research was funded by the National Research Agency (ANR - TRAJUNI Project).
} 


\section{I- Introduction}

The central role of promotions in organizations has been a major focus of the literature on careers. Promotions have two goals (Milgrom and Roberts, 1992). First, they aim to improve the organizations' performance by assigning employees to the jobs that best suit their abilities. Second, they serve as incentives (see Gibbons and Waldman, 1999, and Prendergast, 1999, for a survey). The tournament model (Lazear and Rosen, 1981) illustrates this second role well. Imagine a firm in which all the workers initially have the same low-ability-level job for which they all receive the same wage. Able workers are then promoted to jobs that demand higher levels of ability and that are rewarded with higher wages. The greater the wage-difference between the two jobs, the greater the incentive to work hard. Promotions can also boost performance by providing incentives for higher human-capital investment (Carmichael, 1983; Prendergast, 1993) and by increasing job satisfaction (Francesconi, 2001).

However, this conventional view of promotions is increasingly being called into question, as it is recognized that promotions can also have negative consequences (Baker et al., 1998).

Numerous examples of reductions in productivity after promotion can be seen in the real world, including in universities. For example, the productivity of American university professors has been observed to decline after tenure is obtained (Lazear, 2004). In order to be promoted to full professor, assistant professors must publish more than the average; hence, the quest for tenure tends to boost productivity. However, this external, and thus extrinsic, incentive vanishes once tenure, which is generally not reversible, has been obtained. Conversely, assistant professors who are denied tenure must move to other universities and publish more. Finally, promotion decisions seem to strongly influence expost effort.

The present study tests whether or not productivity also decreases after being promoted (or not) in the French university system. The French and American systems are very different in that French professors are recruited as civil servants on permanent contracts. Therefore, in France, promotions are about obtaining higher pay and extra responsibilities, rather than gaining tenure. In addition, professors can be viewed as motivated workers, who are influenced more by intrinsic incentives than by extrinsic incentives (Besley and Ghatak, 2005). Consequently, the impact of being promoted or not on effort may be different from what has been observed in the American system. Furthermore, France is currently experiencing a move towards greater evaluation of public-sector workers in all fields, including the university sector. As a result, the work of academics is coming under increasing scrutiny, in terms of both teaching and research, and the Ministry of Education is expected to introduce wide-ranging reforms in professors' career structures and promotion procedures (see the Schwartz Report, 2008). However, the promotion system has never been properly evaluated - a situation the present study remedies.

In order to carry out this evaluation, an original dataset of publication scores and promotions of university professors in the field of business studies was created. Because most promotions are awarded on the basis of a centralized promotion procedure, called the concours d'agrégation, the study focused on this procedure. The database contained 
information about promotion decisions (and their explanatory factors), and could be used to evaluate candidates' publication records before and after the promotion procedure. For the purposes of the present study, publications were divided into three categories: articles in international journals, articles in national journals, and books. The quality of each publication was also taken into account.

A major problem facing all evaluations of this type is the impossibility of knowing how productive a person would have been if promotion had not been granted (Rubin, 1974). This difficulty was addressed by using matching methods to obtain unbiased evaluations of the impact of promotions (Heckman et al., 1997, 1998). Data from the growing literature on careers in academia was used to calculate propensity scores; that is to say, the probability of being promoted. Because empirical studies of the determinants of promotion have highlighted the effects of gender (Ginther and Hayes, 1999, 2003; Long et al., 1993), productivity (Mc Dowell et al., 2001) and networks (Combes et al., 2008), all these factors had to be included in order to obtain robust propensity scores. These propensity scores were then used to calculate counterfactual publication scores and to compare productivity before and after promotion. In addition, a sensitivity analysis was carried out to test the plausibility of the Conditional Independence Assumption that underlies all matching estimates (Ichino et al., 2008).

The following section explores the impact of being promoted (or not) on ex-post productivity in the light of both extrinsic and intrinsic incentives, and examines possible ways of evaluating changes in productivity. Section 3 describes the dataset and Section 4 presents a discussion of the results of the matching estimates and of the sensitivity analysis.

\section{II- The effect of promotions on ex-post productivity}

\section{Promotions, incentives and productivity}

Tournament models (Lazear and Rosen, 1981) and numerous related empirical studies have clearly demonstrated that the prospect of promotion encourages employees to make greater efforts in order to maximize their chances of promotion. However, this positive ex-ante impact often seems to be followed by a slight decrease in effort after promotion. The literature contains two explanations for this decrease: a) a reduction in incentives, b) the effect of unobserved abilities.

Within the principal-agent framework, incentives are considered to influence a worker's effort both before and after promotion (Prendergast, 1999). Therefore, firms must try to maintain strong incentives for workers throughout their careers, for example, by organizing dynamic tournaments (Meyer, 2002). However, these procedures have high direct costs, particularly in terms of organization time, leaving less time available for checking the worker's effort. As a result, dynamic tournaments may increase uncertainty in the promotion procedure. Given these negative impacts, organizations may prefer to reward workers via a single promotion procedure. In this case, once promotion decisions are known, most external incentives vanish for promoted candidates. Therefore, the absence of future rewards may explain why 
effort sometimes declines following promotion. Conversely, workers who are not promoted must increase their productivity if they are to be considered for promotion in the future.

Lazear (2004) suggests a second explanation for this fall in productivity, maintaining that the decline starts whenever promotion is based on both permanent and transitory components of ability. Transitory components can distort assessments of workers' true abilities, as it is often difficult to measure and differentiate between actual performance and strategic behaviors. In addition, it is not always easy to ascertain whether or not a candidate has the skills required by the higher position. Because firms have difficulty in distinguishing between permanent and transitory abilities, they tend to promote workers who have sufficient overall pre-promotion abilities. However, the expected value of the post-promotion transitory component is zero, leading to a reduction in the productivity of promoted workers.

Finally, because workers clearly respond to positive external incentives before promotion and to the reduction in such incentives after promotion, the individual effort produced by promoted workers would be expected to decline (and the effort produced by non-promoted workers to increase). Barmby et al. (2006) confirmed the expected fall in post-promotion outputs in a large British financial firm. They concluded that two-thirds of this fall could be attributed to Lazear's theory of decline (2004), and one-third to reduced incentives.

This raises the question of whether or not such a decline in post-promotion productivity occurs in academia, given that both the above two explanations assume that a worker's effort depends only on external incentives, that is, on extrinsic motivation. However, this hypothesis has been strongly contradicted by the psychology literature, which shows that the amount of effort produced by a worker depends on intrinsic motivation as well as on extrinsic motivation (Frey, 1997a). Intrinsic motivation is measured in terms of effort displayed in the absence of external rewards (Deci, 1975). As De Varo and Brookhire (2007) pointed out, intrinsic motivation depends on particular attributes of jobs or on the organization's missions. For example, in nonprofit organizations that provide collective goods, such as the French education system, intrinsic motivation seems to play a more important role than extrinsic motivation. Professors can thus be considered motivated workers, or 'agents who pursue goals because they perceive intrinsic benefits from doing so' (Besley and Ghatak, 2005). In this context, motivated workers are less influenced by financial incentives than in the private sector (De Varo, Brookshire, 2007; Narcy, 2009). This may be reinforced in French academia because professors are recruited as civil servants and immediately given long-term contracts. Consequently, promotion decisions will not change their job security. In addition, a crowding-out effect may occur (Frey, 1997b, Bénabou, Tirole, 2003), with rewards and punishments decreasing intrinsic motivation and leading to lower performance.

Hence, viewing university professors as motivated workers suggests that they may be less sensitive to rewards than other workers. Therefore, the decline in professors' productivity following promotion that is predicted by agency theory may be small or even zero. The present study was designed to test this hypothesis by examining the effect of promotion on ex-post productivity in French academia. 


\section{The evaluation framework}

In order to measure the impact of being promoted or not, it was first necessary to overcome the problem of how to evaluate performance differentials (Rubin, 1974). This problem can be presented as follows. Candidates for promotion are denoted $i$. Their personal attributes (age, gender, etc.) are defined in a vector, $x$. A binary variable, $C$, denotes whether a candidate was promoted to the senior professor rank (the treatment group, $C=1$ ) or not (the reference group, $C=0$ ).

Candidates' publication performances are evaluated via a single indicator, publication score, which is a measure of the number of journal articles and books a candidate has published (see Section 3 for more details and a discussion). Publication scores for candidates who are promoted and for candidates denied promotion are denoted $P_{1}$ and $P_{0}$, respectively. If there is no interference between units, potential outcomes depend on the treatment received, and not on what treatments other units receive. This assumption, named Stable Unit Treatment Value Assumption ${ }^{2}$ by Rubin (1986), allows to define $P_{1}$ and $P_{0}$ as mutually exclusive outcomes that cannot be observed simultaneously. The observed outcome is thus given by:

$$
P=C P_{1}+(1-C) P_{0}
$$

The impact of promotion on a candidate's publication score is the difference between the candidate's observed publication score after promotion and the mean publication score the candidate would have obtained if promotion had been refused. This can be expressed as:

$$
\alpha(x)=E\left[P_{1} / C=1, X=x\right]-E\left[P_{0} / C=1, X=x\right]
$$

The second term defines the counterfactual publication score; that is to say, the hypothetical (and therefore unobservable) score successful candidates would have obtained if they had not been promoted.

To estimate $\alpha(x)$, the counterfactual publication score must be calculated. A number of experimental and non-experimental methods are available to do this (see Heckman et al., 1999; Brodaty et al., 2007). Because the present study was based on a non-experimental dataset consisting of publication scores and promotion data for business studies professors, a non-experimental method had to be used. The most widely used non-experimental method is based on matching estimators, which involves matching each successful candidate, $i$, with an unsuccessful candidate, $\tilde{i}$, with the same characteristics, $x$. As no two individuals are entirely similar in all observable attributes, the matching process was based on propensity scores; that is to say, on the probability of being promoted (treatment probability). This probability was estimated using a probit model. In line with McDowell et al. (2001) and Combes et al. (2008), the present study introduced past productivity scores and network variables as explanatory factors of success at the promotion procedure, taking into account both research quality and peer-rich effects. Individual attributes (gender and past career characteristics), and amount of competition (vacancy to candidate ratio) were also included (Ginther and Hayes, 1999, 2003; Long et al., 1993). Research department quality may also influence the probability of being promoted; however, no chronological data on departments' members or their publications are available, so it was impossible to include information on

\footnotetext{
${ }^{2}$ The SUTVA assumption is here assumed to be valid as publication scores of a given candidate do not depend on the fact that other candidates are promoted (or not).
} 
research department quality in the dataset. Details of the available variables are described below. As matched individuals are considered to be identical, the publication scores of unsuccessful candidates were used to estimate the counterfactual scores of promoted candidates (Rosenbaum and Rubin, 1983). To be efficient, this method must respect the Conditional Independence Assumption (CIA), that is, promotion must only depend on the observables (see Section 4 for a discussion).

Of all the available matching methods (nearest-neighbor estimators, radius matching, kernel matching, etc.), kernel-matching methods applied to the evolution of outcomes (difference in difference $)^{3}$ have been found to give the most robust estimates for $\alpha(x)$ in large samples (Heckman et al., 1997, 1998).

The kernel-matching estimator is defined as:

$$
\hat{\alpha}=\frac{1}{N_{1}} \sum_{i \in A_{1}}\left[\Delta P_{i}-\sum_{j \in A_{0}} \Delta P_{j} \times \frac{\left.K^{\left[\left(C\left(x_{j}\right)-C\left(x_{i}\right)\right) / h\right.}\right]}{\sum_{j \in A_{0}} K\left[C\left(x_{j}\right)-C\left(x_{i}\right) / h\right]}\right]
$$

where $\Delta P=P-P_{t-1}, N_{1}$ is the number of promoted candidates, $K$ is a kernel function with $\int_{-\infty}^{+\infty} K(u) d u=1$, and $h$ is a bandwidth function.

Frölich (2004) demonstrated the finite-sample properties of kernel-matching estimators when the control (non-promoted) to treated (promoted) ratio is large, as was the case in the present sample (346 non-promoted and 280 promoted candidates). Hence, this method was used to evaluate the effect of being promotion decisions on the publication scores of both successful and unsuccessful candidates. A sensitivity analysis was also performed for the matching estimators and the plausibility of the Conditional Independence Assumption was tested. A positive result shows that pre-promotion variables can be used to efficiently match promoted and non-promoted professors. However, a negative result (Conditional Independence Assumption not plausible) indicates that promoted and non-promoted professors also differ according to unobservable attributes. As the data do not provide information on the distribution of $P_{0}$ for promoted professors, the CIA cannot be directly tested. Hence, Ichino et al.'s method (2008) was used to assess the robustness of matching estimators (see Section 4 for the results of the sensitivity analysis).

\footnotetext{
${ }^{3}$ This allows the elimination of unobservable individual effects.
} 


\section{III- Data and method}

\section{Promotions in the French university system}

French universities recognize two ranks of professor: maitre de conferences (equivalent to assistant professor in the US university system) and professeur des universities (equivalent to full professor). The present study focused on the field of business studies. In this field (and in Economics, Law and Political Sciences ${ }^{4}$ ), promotion from assistant professor to full professor can be obtained either via a centralized procedure known as the concours d'agrégation, or via a decentralized procedure (mainly through local selection committees). These two promotion procedures are governed by very different rules.

Two types of concours d'agrégation exist. The first concours is an external competition and is open to anybody with a Ph.D., no matter how much experience (if any) they have as an assistant professor. The second concours, is an internal competition that is only open to assistant professors who are at least 40 years old and who have at least 10 years experience. As only four internal competitions have been organized since 1979 (47 assistant professors have been promoted via this method), $67 \%$ of promotions to the full professor rank have been awarded by external concours d'agrégation, in which promotion decisions are mainly based on research achievements.

In contrast, the decentralized procedure is only open to assistant professors with at least ten years experience. As well as publication scores, these promotion decisions take into account administrative duties, such as managing departments.

Because the decentralized procedure is very different from the concours d'agrégation and because the concours d'agrégation is the main route to promotion for French business studies professors, the present study only examined the external concours d'agrégation.

In order to evaluate the impact of the promotion procedure on publication scores, it was first necessary to determine the probability of being promoted. This probability was then used to estimate propensity scores, which was the first step of the evaluation procedure described above.

As can be seen in figure 1, the timetable for the concours d'agrégation is very long (Combes et al., 2008).

\footnotetext{
${ }^{4}$ In other disciplines, the concours d'agrégation does not exist and all promotions are decided by decentralized procedures.
} 
Figure 1.

The timetable for the concours d'agrégation

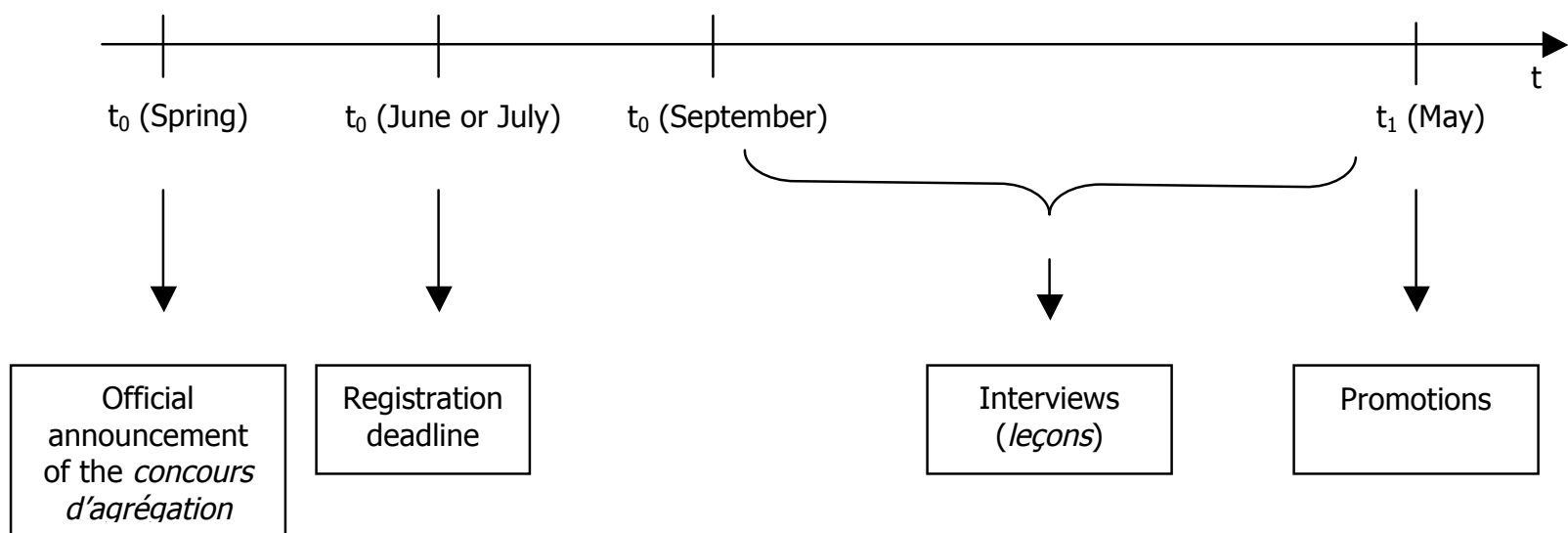

When details of the promotion procedure are announced, potential candidates are told how many full professorships are available and the registration deadline. The names of the jury members are announced before the registration deadline. The Ministry of Education chooses the president of the jury from amongst France's most experienced full professors in the relevant field. Other members are nominated by the President and appointed by the Ministry. Jury members are usually well-known researchers, although not all work in the university sector, and they may be from France or abroad. Despite being appointed by the Ministry of Education, jury members are independent. When candidates register for the concours d'agrégation they are not informed where the available full-professor posts are located. Between September and May, the jury carries out several interviews (leçons), during which they assess the candidates' research. In May (or June), the jury announces the names of the successful candidates and their rankings. The locations of the available positions are then revealed, and the successful candidates choose their preferred location according to their ranking (i.e., the candidate ranked first can choose from all the available positions, the candidate ranked second can choose from the remaining positions and so forth). There are three major differences between the French and American promotion procedures. First, in France, assistant professors are granted tenure soon after they are hired (university professors are civil servants and French civil servants have excellent job security). As a result, the main motivation for seeking promotion is not to obtain job security, but to further one's career in terms of salary, duties and mobility. Second, promoted candidates are likely to have to move to a different university, as there may not be any positions available in their current university, or they may not be ranked high enough to be able to choose their current university. Conversely, unsuccessful candidates generally do not leave their university. Third, universities cannot choose their full professors (Combes et al., 2008). 


\section{Dataset}

Fourteen business-studies external concours d'agrégation were held between 1979 and 2007. The Ministry of Education granted full access to its concours d'agrégation database, which contains the names of the candidates and the members of the juries for all 14 sessions, as well as personal data about the candidates (gender, age, etc.) and information about the juries' decisions. The present study only considered candidates who were assistant professors when they applied for promotion, thereby excluding applicants from outside the university system. This provided a database of 502 assistant professors who went through the promotion procedure to try and become full-professors. Forty-two percent of these candidates were successful.

The name of each candidate's Ph.D. supervisor and the date the candidate obtained his/her Ph.D. were extracted from the SUDOC database and added to the Ministry of Education data ${ }^{5}$. This database also includes the name of the university that awarded the Ph.D. It is widely recognized that the prestige of the university awarding a Ph.D. strongly influences future career possibilities: professors with Ph.D.s from the best universities obtain the best positions and have the best chances of being promoted (Crane, 1965; Long et al., 1979). France's most prestigious university for business studies is the University of Paris 9, which is seen as the birthplace of business studies in France. Paris 9 still attracts the best students and the best professors.

The SUDOC data were also used to calculate the lengths of post-Ph.D. careers and the professional links between a candidate and members of the jury. By noting whether or not a candidate's Ph.D. supervisor was a member of the jury, it was possible to take into account peer-rich effects due to Ph.D. supervisors favoring past students and influencing other members of the jury. Combes et al. (2008) showed that networking has a significant and positive effect on the promotion prospects of economists teaching in French universities. In order to obtain a more complete picture of the influence of former Ph.D. supervisors, a further variable was added: whether or not a candidate's Ph.D. supervisor was a member of another jury. This variable can affect decisions in two ways. First, Ph.D. supervisors in another jury (before the candidate applies) could inform candidates about promotion criteria and competition rules, without giving direct support. Second, as only well-known academics are asked to sit on juries, being a member of a jury is an indicator of a Ph.D. supervisor's reputation.

Finally, the average annual publication record of each candidate before and after the promotion procedure ${ }^{6}$ was examined as a proxy for productivity. Hence mean annual publication scores were calculated for the periods before and after (up to 2009) the promotion procedure. This gives a global indicator, supposing that individual scientific production is homogenous in the pre-promotion and in the post-promotion observation periods. In order to assess the sensitivity of the results with respect to this hypothesis, four indicators of scientific production were examined: the global indicator presented above and

\footnotetext{
${ }^{5}$ For 12 candidates among the 502 observed, no information was found in the SUDOC database. Our sample is thus reduced to 490 candidates.

${ }^{6}$ Evaluations were based on publication scores calculated before and after the concours. A second pre-concours publication score was also calculated, based on the number of publications published up until one year after the concours, in order to take into account the fact that candidates' CVs include forthcoming publications, which are therefore known to the jury (Combes et al., 2008). This measure of publication scores did not have a statistically significant effect on the results.
} 
three indicators based on publications published two years (for all competitions), four years (for competitions held between 1979 and 2005) and six years (for competitions held between 1979 and 2003) before and after the promotion procedure. The matching estimators showed that the results for the four indicators were similar (Appendix 1). Hence, assuming homogenous scientific production over time did not affect the results.

Three types of publication were recorded: (a) articles in international journals (collated from the Econlit and Business Source Premier electronic databases); (b) articles in French journals, collated from the author lists for all the abstracts published by the main French business studies journals; (c) books, collated from the French National Library's electronic database. All the publication indicators cover the full range of publications. Three indicators do not take into account journal-ranking systems; but the fourth indicator calculates publication scores on the basis of the number of articles published weighted according to the prestige of the journal (using the Science Citation Index). The number of articles and/or books published by a candidate before and after the promotion procedure was also weighted according to the number of years between the candidate's Ph.D. and the promotion procedure, and according to the number of years between the promotion procedure and 2009.

Table 1 summarizes all the variables that were used in the econometric analysis.

The differences between promoted ("treated" column) and non-promoted professors ("all controls" column) suggest that the promotion procedure favors candidates who have more rapid careers (that is, they obtain their Ph.D. younger and go through the promotion procedure sooner after obtaining their Ph.D.), who obtained their Ph.D. from the University of Paris 9, who have published more, and who were assessed by a jury that included their Ph.D. supervisor (Table 1). Unlike previous research into academic careers (Ginther and Hayes, 1999, 2003), a large gender effect did not emerge.

These descriptive findings were used to calculate the probability of successfully completing the concours d'agrégation and to identify matched controls (see below). The matched controls and treated categories have very similar observable characteristics; therefore it was possible to evaluate the effect of promotion on productivity (Table 1). 
TABLE 1

Pre-treatment characteristics

\begin{tabular}{|lccc|}
\hline Variable & & & Matched \\
\hline Control variables & Treated & All controls & controls \\
\hline Number of positions/Number of candidates & & & \\
Male & 0.456 & 0.391 & 0.449 \\
Age when Ph.D. awarded & 0.769 & 0.756 & 0.765 \\
Number of years between Ph.D. and the promotion procedure & 30.367 & 32.007 & 31.009 \\
Number of previous applications & 5.286 & 7.626 & 6.578 \\
Ph.D. from Paris 9 & 1.348 & 1.498 & 1.314 \\
Ph.D. supervisor on the jury & 0.176 & 0.121 & 0.151 \\
Ph.D. supervisor on another jury & 0.111 & 0.022 & 0.019 \\
Publication scores before the promotion procedure & 0.211 & 0.198 & 0.207 \\
\hline Publication differential before and after the promotion procedure & 4.678 & 0.564 & 4.393 \\
\hline Total differential & & & \\
Differential for international journals & -0.290 & -0.194 & -0.179 \\
Differential for French journals & -0.016 & -0.010 & 0.012 \\
Differential for books & -0.035 & -0.177 & -0.002 \\
Differential for quality-weighted publications & -1.226 & -0.269 & -0.0479 \\
\hline No. of observations & -0.289 & -0.007 & -0.179 \\
\hline
\end{tabular}

Notes: Matched controls are individuals who belong to the control sample, based on the propensity score estimate shown in Table 2.

Table 1 also presents publication differentials before and after the promotion procedure for all the candidates. Annual productivity scores were lower after the concours for all types of publication. However, this differential was greater for the treated group than for the control group $(-0.290$ and -0.194 , respectively).

These descriptive statistics suggest that productivity decreases after promotion; however, such simplistic observations may be biased because promoted and non-promoted candidates have different profiles.

\section{IV- The effect of promotion on productivity scores: matching estimates}

\section{Results}

In order to correct for selectivity bias, kernel-matching methods (see section II) were used to estimate counterfactual publication scores for the promoted and non-promoted candidates. These scores were then used to determine unbiased productivity differentials. The results of the two steps of the analysis - the calculation of propensity scores (the probability of achieving promotion via the concours) and the calculation of publication differentials using kernel-matching methods - are presented below. In order to analyze the results in more detail, two different sub-groups, based on gender, were examined in addition to the full sample.

Table 2 presents the results of the first step. 

TABLE 2

Probability of being promoted - propensity scores

\begin{tabular}{|c|c|c|c|c|c|c|}
\hline & \multicolumn{2}{|c|}{ Full sample } & \multicolumn{2}{|c|}{ Male } & \multicolumn{2}{|c|}{ Female } \\
\hline & Coef. & $\begin{array}{l}\text { Standard } \\
\quad \text { error }\end{array}$ & Coef. & $\begin{array}{l}\text { Standard } \\
\text { error }\end{array}$ & Coef. & $\begin{array}{l}\text { Standard } \\
\quad \text { error }\end{array}$ \\
\hline Number of positions/Number of candidates & 2.240 & $0.434^{* * *}$ & 2.409 & $0.493^{* * *}$ & 2.259 & $0.993^{* *}$ \\
\hline Male & 0.060 & $0.158^{\mathrm{ns}}$ & & & & \\
\hline Age when Ph.D. awarded & -0.076 & $0.015^{\star * *}$ & -0.096 & $0.018^{* * *}$ & -0.031 & $0.035^{\mathrm{ns}}$ \\
\hline $\begin{array}{l}\text { No. of years between Ph.D. and the promotion } \\
\text { procedure }\end{array}$ & -0.140 & $0.020^{* * *}$ & -0.157 & $0.023^{* * *}$ & -0.105 & $0.051^{* *}$ \\
\hline Number of previous applications & -0.086 & $0.112^{\mathrm{ns}}$ & -0.084 & $0.125^{\mathrm{ns}}$ & -0.116 & $0.293^{\text {ns }}$ \\
\hline Ph.D. from Paris 9 & 0.191 & $0.186^{\mathrm{ns}}$ & 0.189 & $0.231^{\mathrm{ns}}$ & 0.342 & $0.334^{\mathrm{ns}}$ \\
\hline Ph.D. supervisor in the jury & 1.272 & $0.336^{* * *}$ & 1.369 & $0.384^{* * *}$ & 1.327 & $0.784^{*}$ \\
\hline Ph.D. supervisor in another jury & 0.090 & $0.162^{\mathrm{ns}}$ & 0.024 & $0.190^{\mathrm{ns}}$ & 0.254 & $0.336^{\text {ns }}$ \\
\hline Publication scores before & 0.100 & $0.019^{* * *}$ & 0.078 & $0.021^{* * *}$ & 0.262 & $0.063^{* * *}$ \\
\hline Constant & 1.700 & $0.552^{* * *}$ & 2.532 & $0.657^{* * *}$ & -0.559 & $1.197^{\mathrm{ns}}$ \\
\hline Log Likelihood & \multicolumn{2}{|c|}{-244.051} & \multicolumn{2}{|c|}{-182.750} & \multicolumn{2}{|c|}{-58.941} \\
\hline No. of observations & \multicolumn{2}{|c|}{450} & \multicolumn{2}{|c|}{345} & \multicolumn{2}{|c|}{105} \\
\hline
\end{tabular}

Notes: ***: significant at $1 \%, * *$ : significant at $5 \%, *$ : significant at $10 \%$ and ns: non significant

In terms of the results for the control variables, the coefficient for the number of positions/number of candidates ratio is significantly positive, indicating that less competition means a higher probability of success. The results also show that youth is an advantage, as candidates who obtained their Ph.D. at a young age and candidates who applied for promotion soon after obtaining their Ph.D. had a greater chance of being promoted. In line with Combes et al. (2008), significant effects were found for past productivity and network connections. In the case of network connections, the probability of being promoted appears to be higher for a candidate whose Ph.D. supervisor was on the jury, but this was not the case if the supervisor was a member of another jury. Hence, peer-rich effects seem to be more important than information or reputation effects. In addition, despite its reputation, a Ph.D. from the University of Paris 9 had no effect on the probability of being promoted. It is also interesting that there was no significant effect of gender, which is in marked contrast to other studies of promotion in academia (Ginther and Hayes, 1999, 2003; Long et al., 1993). In fact, the problem facing females in French academia seems to be more of a "sticky floor" than a "glass ceiling", as females are severely under-represented among candidates for promotion, although they have the same success rate as men when they do apply. A nonsignificant effect of gender has also been reported for the field of economics (Combes et al., 2008).

Similar results were obtained for most of the sub-samples. These results were used to estimate propensity scores. These scores allow us to match "equivalent" treated and nontreated ${ }^{7}$. The candidates were divided into five homogenous blocks. As each of these blocks has a valid balancing hypothesis (that is the average propensity score of treated and matched controls does not differ), the publication scores of non-promoted candidates could

\footnotetext{
${ }^{7}$ Among the 291 controls, 40 individuals have very different observed characteristics (especially in terms of age) from those of the promoted persons. These outliers thus have been excluded from the analysis.
} 
be used to estimate counterfactual propensity scores for promoted candidates (and vice versa). Kernel matching was used to estimate the unbiased differentials in publication scores before and after the concours d'agrégation for both successful and unsuccessful candidates. The results of these estimates are shown in Table 3. Publication differentials were estimated for promoted and non-promoted candidates for all publications (column 1), for articles in international journals (column 2), for articles in French journals (column 3) and for books (column 4). The impact of promotions on publication scores was estimated for the full sample and for the four sub-samples.

TABLE 3

Publication-score differentials before and after promotion

\begin{tabular}{|c|c|c|c|c|c|}
\hline & $\begin{array}{c}1) \\
\text { Total } \\
\text { differential }\end{array}$ & $\begin{array}{c}(2) \\
\text { Differential for } \\
\text { international } \\
\text { journals }\end{array}$ & $\begin{array}{c}(3) \\
\text { Differential for } \\
\text { French journals }\end{array}$ & $\begin{array}{c}(4) \\
\text { Differential } \\
\text { for books }\end{array}$ & $\begin{array}{c}\text { (5) } \\
\text { Differential for } \\
\text { quality } \\
\text { weighted } \\
\text { publications }\end{array}$ \\
\hline \multicolumn{6}{|c|}{ Promoted candidates } \\
\hline Full sample & $\begin{array}{c}0.210 \\
(0.179)^{\text {ns }}\end{array}$ & $\begin{array}{c}-0.008 \\
(0.150)^{\mathrm{ns}}\end{array}$ & $\begin{array}{c}0.177 \\
(0.089)^{\star *}\end{array}$ & $\begin{array}{c}-0.429 \\
(0.694)^{\mathrm{ns}}\end{array}$ & $\begin{array}{c}0.052 \\
(0.110)^{\mathrm{ns}}\end{array}$ \\
\hline Male & $\begin{array}{c}0.243 \\
(0.213)^{\text {ns }}\end{array}$ & $\begin{array}{c}-0.029 \\
(0.157)^{\mathrm{ns}}\end{array}$ & $\begin{array}{c}0.192 \\
(0.118)^{\mathrm{ns}}\end{array}$ & $\begin{array}{c}-0.668 \\
(0.759)^{\text {ns }}\end{array}$ & $\begin{array}{c}0.070 \\
(0.120)^{\text {ns }}\end{array}$ \\
\hline Female & $\begin{array}{c}0.132 \\
(0.221)^{\mathrm{ns}}\end{array}$ & $\begin{array}{c}0.216 \\
(0.179)^{\mathrm{ns}}\end{array}$ & $\begin{array}{c}0.104 \\
(0.144)^{\mathrm{ns}}\end{array}$ & $\begin{array}{c}0.360 \\
(0.638)^{\text {ns }}\end{array}$ & $\begin{array}{c}0.041 \\
(0.102)^{\mathrm{ns}}\end{array}$ \\
\hline \multicolumn{6}{|c|}{ Non-promoted candidates } \\
\hline Full sample & $\begin{array}{c}-0.229 \\
(0.101)^{* *}\end{array}$ & $\begin{array}{c}-0.020 \\
(0.037)^{\mathrm{ns}}\end{array}$ & $\begin{array}{c}-0.141 \\
(0.064)^{* *}\end{array}$ & $\begin{array}{c}-0.430 \\
(0.612)^{\text {ns }}\end{array}$ & $\begin{array}{c}-0.133 \\
(0.056)^{\star * *}\end{array}$ \\
\hline Male & $\begin{array}{c}0.242 \\
(0.199)^{\text {ns }}\end{array}$ & $\begin{array}{c}0.030 \\
(0.150)^{\text {ns }}\end{array}$ & $\begin{array}{c}0.198 \\
(0.117)^{\text {ns }}\end{array}$ & $\begin{array}{c}-0.679 \\
(0.723)^{\text {ns }}\end{array}$ & $\begin{array}{c}-0.103 \\
(0.090)^{\mathrm{ns}}\end{array}$ \\
\hline Female & $\begin{array}{c}-0.328 \\
(0.148)^{\star *}\end{array}$ & $\begin{array}{c}-0.033 \\
(0.049)^{\text {ns }}\end{array}$ & $\begin{array}{c}-0.247 \\
(0.111)^{\star *}\end{array}$ & $\begin{array}{c}0.345 \\
(0.597)^{\text {ns }}\end{array}$ & $\begin{array}{c}-0.099 \\
(0.106)^{\text {ns }}\end{array}$ \\
\hline
\end{tabular}

Notes 1: Bootstrapped standard errors (obtained after 1,000 replications) are given in brackets.

Notes 2: ***: significant at $1 \%, * *$ : significant at $5 \%, *$ : significant at $10 \%$ and ns: non significant

The results presented in table 3 suggest that being promoted does not lead to a substantial decline in publication score. Most of the results for the promoted candidates were not significant. Exceptions to this rule are articles in French journals for the full sample, for which the estimated differential was positive.

Kernel-matching estimates for candidates who were denied promotion gave negative differentials; that is to say, candidates denied promotion published significantly less after the promotion procedure. This result is most apparent for females, for articles in French journals, and for the publication of books by the most recent cohorts.

These results clearly contradict the predictions of agency theory and of Lazaer (2004), as publication scores did not decrease for promoted candidates, but they did decrease for candidates who were denied promotion.

In fact, all the explanatory factors for the fall of productivity after promotion suppose that incentives disappear following promotion. This seems to be incorrect in the case of French 
academia for two main reasons. First, any reduction in extrinsic incentives for French academics is likely to be minimized by the fact that most newly promoted full professors have to move to a new university. As a result, they have to join a new research department, develop new contacts and build a reputation. The resulting peer pressure may limit free-rider behavior and maintain overall productivity. In addition, because successful candidates choose their preferred location according to their ranking, the lowest ranked professors may be required to go universities they would not otherwise have chosen. Full professors who are unhappy with their posting can subsequently apply for a transfer. Such transfers are more likely to be accorded to professors with good publication scores, thereby providing another incentive to be productive.

Second, although there is less of a decrease in extrinsic motivation for promoted professors in France, intrinsic motivations remain unchanged following promotion. If professors are motivated workers (Besley and Ghatak 2005), they will be relatively insensitive to promotion and they are likely to continue publishing at the same rate. This is reinforced by the fact that, in France, assistant professors and full professors often have similar roles. Consequently, most of the skills required to obtain promotion from the assistant professor rank are the same as the skills required to successfully carry out the role of full professor.

The decrease in productivity recorded for assistant professors who are denied promotion may be due to the fact that the concours is the main route to promotion. As failure at the promotion procedure can be viewed as the end of any likelihood of promotion, being denied promotion may lead to a major decrease in motivation and therefore to a lower publication score. This effect may be reinforced by the facts that assistant professors in France are civil servants with guaranteed job security and that low productivity will not result in sanctions. In addition, unsuccessful candidates for the concours d'agrégation who decide to try and obtain promotion through the decentralized procedure (direct negotiations with universities) are likely to focus on administrative duties, as such tasks are a major promotion criterion in this procedure. As administrative duties are highly time-consuming, they tend to substantially reduce publication scores.

In summary, the results do not show any change in publication scores for French business studies professors who are promoted to full professor rank via the concours d'agrégation; therefore, there is no evidence for a decline in productivity after promotion. However, 58\% of candidates for promotion are unsuccessful and this failure leads to a significant reduction in productivity, suggesting that the promotion procedure may have deleterious effects.

\section{Results of the sensitivity analysis}

A sensitivity analysis was carried out to determine the robustness of the matching estimates when the CIA is not satisfied; that is to say, when the probability of being promoted is not random within each cell defined by the observables, $x$. This would occur if there were differences between promoted and non-promoted professors in terms of unobservable abilities. Consequently, it is essential to test the reliability of the CIA. This was done using the method developed by Ichino et al. (2008). A summary of the reasoning on which this 
sensitivity analysis is founded is presented below (based on Rosenbaum and Rubin, 1983, Rosenbaum, 1987 and Imbens, 2003).

If the CIA is not satisfied given $x$, but is satisfied when it includes an additional binary confounding factor, $U$, which measures an unobservable ability component, then: $E\left[P_{0} / C=1, x\right] \neq E\left[P_{0} / C=0, x\right]$, but: $E\left[P_{0} / C=1, x, U\right]=E\left[P_{0} / C=0, x, U\right]$.

Following Rosenbaum and Rubin (1983), the distribution of $U$ is fully specified by the choice of four parameters, given by:

$$
s_{i j}=\operatorname{Pr}\left(U=1 / C=i, I\left(P>p^{*}\right)=j\right)=\operatorname{Pr}\left(U=1 / C=i, I\left(P>p^{*}\right)=j, x\right)
$$

with $i, j \in\{0,1\}$ and where $I$ is the indicator function and $p^{*}$ is the median of the distribution of the publication scores, $P^{8}$.

The parameters $s_{i j}$ give the probability that $U=1$ in each of the four groups defined by promotion status and outcomes. For example, if people for whom $U=1$ are denoted skilled people, $s_{11}$ can be defined as the fraction of skilled candidates among those who are promoted $(C=1)$ and who publish more than the median.

Once a distribution for $U$ has been chosen, $U$ can be simulated in the data. The first step is to define the values of the parameters (Ichino et al., 2008), $s_{i j}$. This can be accomplished in two different ways: (1) Values for each $s_{i j}$ can be arbitrarily chosen, for example: $s_{11}=s_{10}=s_{01}=s_{00}=0.5$, which defines a neutral confounder. (2) $U$ can be calibrated to mimic important observable covariates. For example, suppose that the distribution of $U$ is similar to the distribution of gender. The academic promotions dataset shows that $79 \%$ of the individuals who are promoted and who have a higher publication score than the median are male. Hence, $s_{11}$ is set at 0.79 , that is to say $79 \%$ of people in the sample are skilled and have $U=1$. Finally, it is implicitly assumed that promoted candidates are more "skilled" than the controls (non-promoted candidates).

Both techniques enable a value of $U$ to be attributed to each individual, according to which of the four defined groups that person belongs. The simulated $U$ is then used as an additional covariate to estimate new propensity scores and kernel matching estimates ${ }^{9}$. A comparison of the estimates obtained with and without the additional variable indicates the extent to which the initial results are robust to this particular failure of the CIA.

Table 4 presents the results of this sensitivity analysis for the global differential in publication scores ${ }^{10}$ for (a) promoted candidates and (b) non-promoted candidates.

In table $4 a$, each row of the first four columns gives the four probabilities, $s_{i j}$, which define the distribution of the unobservable abilities components, $U$, by promotion status and outcome. Column 5 gives the outcome effect of $U$, by estimating a logit model of

\footnotetext{
${ }^{8}$ As outcomes are a continuous variable, a binary transformation of $P$ was used to define the parameters $s_{i j}$ (Nannicini, 2007). Tests using other values for $p^{*}$ (mean, $25^{\text {th }}$ and $75^{\text {th }}$ centiles) showed that the results of the sensitivity analysis were not affected by this choice.

${ }^{9}$ See Ichino et al. (2008) for details on computing standard errors of the simulated kernel matching estimates.

${ }^{10}$ The results of the sensitivity analysis for detailed types of publications are not presented here but are available upon request. The CIA was found to be plausible for all types of publications.
} 
$\operatorname{Pr}(I=j / C=0, U, x)$, with $j \in\{0,1\}$. This outcome effect, noted $\Gamma$, measures the effect of skill on the outcome for non-promoted candidates, after controlling for observables, $x$. Similarly, column 6 presents the selection effect of $U$, noted $\Lambda$, by estimating a logit model of $\operatorname{Pr}(C=i / U, x)$, with $i \in\{0,1\}$. $\Lambda$ measures the impact of $U$ on the probability of being promoted (taking into account covariates $x$ ). Table $4 \mathrm{~b}$ has a similar format to Table $4 \mathrm{a}$.

The first row of Table $4 a$ indicates the initial matching estimate of the global publication differential before and after promotion. The second row gives the simulated matching estimate using a neutral confounder. The other rows present simulated estimates in which $U$ is calibrated to match the distribution of specific covariates.

TABLE 4

Sensitivity analysis

a) Promoted candidates

\begin{tabular}{|c|c|c|c|c|c|c|c|c|}
\hline & \multicolumn{4}{|c|}{$\begin{array}{c}\text { Fraction of } U=1 \text { by promotion } \\
\text { status and outcome }\end{array}$} & \multirow{2}{*}{$\begin{array}{c}\text { Outcome } \\
\text { effect } \\
(\Gamma)\end{array}$} & \multirow{2}{*}{$\begin{array}{c}\text { Selection } \\
\text { effect } \\
(\Lambda)\end{array}$} & \multirow{2}{*}{$\begin{array}{l}\text { Matching } \\
\text { estimator }\end{array}$} & \multirow[t]{2}{*}{$\begin{array}{l}\text { Standard } \\
\text { error }\end{array}$} \\
\hline & $s_{11}$ & $s_{10}$ & $s_{01}$ & $s_{00}$ & & & & \\
\hline Baseline matching estimator & 0.00 & 0.00 & 0.00 & 0.00 & - & - & 0.210 & $0.179^{\mathrm{ns}}$ \\
\hline Neutral confounder & 0.50 & 0.50 & 0.50 & 0.50 & 1.33 & 1.05 & 0.208 & $0.185^{\mathrm{ns}}$ \\
\hline \multicolumn{9}{|l|}{ Confounder-like: } \\
\hline Male & 0.79 & 0.77 & 0.78 & 0.74 & 1.39 & 1.24 & 0.207 & $0.183^{\mathrm{ns}}$ \\
\hline Ph.D. from Paris 9 & 0.19 & 0.15 & 0.13 & 0.15 & 1.09 & 1.59 & 0.206 & $0.179^{\text {ns }}$ \\
\hline Ph.D. supervisor on the jury & 0.74 & 0.67 & 0.73 & 0.83 & 0.77 & 0.62 & 0.203 & $0.173^{\text {ns }}$ \\
\hline Ph.D. supervisor on another jury & 0.23 & 0.20 & 0.20 & 0.17 & 1.26 & 1.15 & 0.210 & $0.123^{\mathrm{ns}}$ \\
\hline
\end{tabular}

b) Non-promoted candidates

\begin{tabular}{|c|c|c|c|c|c|c|c|c|}
\hline & $\begin{array}{r}\text { Fractio } \\
\mathrm{s}\end{array}$ & $\begin{array}{l}\text { of } \square \\
\text { tus an }\end{array}$ & $\begin{array}{l}\text { by pr } \\
\text { outcon }\end{array}$ & notion & $\begin{array}{l}\text { Outcome } \\
\text { effect }\end{array}$ & $\begin{array}{c}\text { Selection } \\
\text { effect }\end{array}$ & $\begin{array}{l}\text { Matching } \\
\text { estimator }\end{array}$ & $\begin{array}{c}\text { Standard } \\
\text { error }\end{array}$ \\
\hline Baseline matching estimator & 0.00 & 0.00 & 0.00 & 0.00 & - & - & -0.229 & $0.101^{* *}$ \\
\hline Neutral confounder & 0.50 & 0.50 & 0.50 & 0.50 & 1.29 & 0.96 & -0.233 & $0.102^{* *}$ \\
\hline Confounder-like: & & & & & & & & \\
\hline Male & 0.77 & 0.74 & 0.80 & 0.75 & 1.31 & 0.88 & -0.227 & $0.091^{* *}$ \\
\hline Ph.D. from Paris 9 & 0.13 & 0.13 & 0.19 & 0.14 & 1.35 & 0.70 & -0.230 & $0.099^{* *}$ \\
\hline Ph.D. supervisor on the jury & 0.76 & 0.80 & 0.67 & 0.69 & 1.31 & 1.85 & -0.234 & $0.101^{* *}$ \\
\hline Ph.D. supervisor on another jury & 0.20 & 0.19 & 0.23 & 0.20 & 1.30 & 0.94 & -0.233 & $0.100^{\star *}$ \\
\hline
\end{tabular}

Notes 1: $U$ defines a binary confounding factor, which is not observed and $S_{i j}$ denotes the fraction of $U=1$, by promotion status and publication score. On the basis of these parameters, a value of $U$ was simulated and used to estimate a kernel-matching estimator (after 1,000 repetitions).

Notes 2: ${ }^{* *}$ : significant at $1 \%,{ }^{* *}$ : significant at $5 \%,{ }^{*}$ : significant at $10 \%$ and ns: non significant

The results of the sensitivity analysis for promoted candidates (table 4a) when the distribution of $U$ is comparable to the gender distribution are examined below. After controlling for observable covariates, skills were found to increase the publication scores for non-promoted candidates $(\Gamma=1.39>1)$ and the probability of being promoted 
$(\Lambda=1.24>1)$. If the CIA is not satisfied when it is attributed these characteristics, the matching estimator is equal to 0.207 . This indicates that the potential confounder $U$ behaves like the gender dummy. It explains only $1.43 \%{ }^{11}$ of the baseline estimate and remains statistically non-significant. Similarly, when the distribution of $U$ is assumed to mimic the distribution of other observable binary covariates, all these variables were found to affect the outcome and the selection effects. However, for the promoted candidates, the simulated matching estimator was always very close to the baseline estimate and always non-significant.

Similarly, the results of the sensitivity analysis for the non-promoted candidates (table 6b) indicate that the simulated matching estimators do not strongly differ from the baseline estimates and remain statistically negative, whatever the type of distribution chosen for $U$. All these simulations support the robustness of the matching estimates, whatever the distribution chosen for $U$. Although unobservable abilities influence the outcome and selection effect, they do not seem to affect the estimate of the publication-score differentials before and after promotion.

\section{IV- Conclusion}

The present research represents the first attempt to empirically test whether or not the productivity of French university professors decreases when they are promoted from assistant professor to full professor. According to the principal-agent framework, being promoted would be expected to lead to a decrease in productivity and failure to obtain promotion would be expected to lead to an increase in productivity. An original and rich dataset was constructed in order to test these predictions for business-studies professors who were promoted or denied promotion via the concours d'agrégation, which is the main procedure for promoting university professors in this field in France. This dataset was used to compare the publication scores of promoted professors with counterfactual publication scores; that is to say, with the publication scores they would have had if they had not been promoted. As counterfactual productivity cannot be observed, this evaluation had to overcome the problem of selectivity bias, which was done by applying kernel-matching methods. The results clearly contradict the predictions of the principal-agent theory, as promotion from assistant professor to full professor was found to have no significant effect on publication scores. Conversely, failure to achieve promotion seems to lead to a marked decline in productivity. A sensitivity analysis (carried out according to the method described by Ichino et al., 2008) supported the robustness of the matching estimates, whatever the distribution chosen for $U$.

The results show that promotion to full professor rank does not lead to a fall in productivity for promoted professors. This may be due partly to new extrinsic incentives arising after promotion; however, the main cause is probably the maintenance of intrinsic motivation. Nevertheless, the results show a slight decrease in publication scores for non-promoted professors.

\footnotetext{
${ }^{11}(0.210-0.207) / 0.210$
} 


\section{References}

Baker, G.P., Jensen, M.C. and Murphy, K.J. (1988). 'Compensation and Incentives: Practice vs. Theory', The Journal of Finance, Vol. XLIII, No.3, pp.593-616.

Barmby, T., Eberth, B. and Ma, A. (2006). 'Thinks Can Only Get Worse? An Empirical Examination of the Peter Principle', Working Paper, University of Aberdeen Business School, No.5.

Benabou, R., J.M. and Tirole, J. (2003). 'Intrinsic and Extrinsic Motivation', Review of Economic Studies, Vol.70, pp.489-520.

Besley, T. and Ghatak, M. (2005), 'Competition and Incentives with Motivated Agents', American Economic Review, Vol.95, pp.616-636.

Brodaty, T., Crépon, B. and Fougère, D. (2007). 'Les méthodes Microéconométriques d'Evaluation et leurs Applications aux Politiques Actives d'Emploi', Economie et Prévision, No.177, pp.93-118.

Carmichael, H.L. (1988). 'Incentives in Academics: Why is there tenure?', Journal of Political Economy, Vol.96, No.53, pp.453-472.

Combes, P-P., Linnemer, L. and Visser, M. (2008). 'Publish or peer-rich? The role of skills and networks in hiring economic professors', Labour Economics, Vol.15, No.3, pp.423-441.

Crane, D. (1965). 'Scientists at Major and Minor Universities: A Study of Productivity and Recognition', American Sociological Review, Vol.30, No.5, pp.699-714.

De Varo, J. and Brookshire, D. (2007). 'Promotions and Incentives in Nonprofit and For-Profit Organizations', Industrial and Labor Relations Review, Vol.60, pp.311-339.

Deci, E.L. (1975). Intrinsic Motivation, New York: Plenum Press.

Francesconi, M. (2001). 'Determinants and consequences of promotions in Britain', Oxford Bulletin of Economics and Statistics, Vol.63, No.3, pp.279-309.

Frey, B. (1997a). Not Just for the Money - An Economic Theory of Personal Motivation, Cheltenham, U.K.: Edward Elgar.

Frey, B.S. (1997b). "On the Relationship between Intrinsic and Extrinsic Work Motivation", International Journal of Industrial Organization, Vol.15, pp.427-39.

Frölich, M. (2004). 'Finite-sample Properties of Propensity-score Matching and Weighting estimators', The Review of Economics and Statistics, Vol.86, No.1, pp.77-90.

Gibbons, M.R. and Waldman, M. (1999). "Careers in Organizations: Theory and Evidence", in Handbook of Labor Economics, ed. O. Ashenfelter and D. Card, Vol.3B, Chap.36, pp.2373-2437, Elsevier, Amsterdam.

Ginther, D.K. and Hayes, K.J. (1999). 'Gender Differences in Salary and Promotion in the Humanities', American Economic Review, Vol.89, No.2, pp.397-402.

Ginther, D.K. and Hayes, K.J. (2003). 'Gender Differences in Salary and Promotion for Faculty in the Humanities 1977-1995', Journal of Human Resources, Vol.38, No.1, pp.34-73.

Heckman, J.J., Lalonde, R.J. and Smith, J.A. (1999). 'The Economics and Econometrics of Active Labor Market Programs', In Handbook of Labor Economics, ed. O. Ashenfelter and David Card, Vol.3A, pp.1865-2097.

Heckman, J.J., Ichimura, H. and Todd, P. (1998). 'Matching as an Econometric Evaluation Estimator', Review of Economic Studies, Vol.65, pp.261-694.

Heckman, J.J., Ichimura, H. and Todd, P. (1997). 'Matching as an Econometric Evaluation Estimator: Evidence from Evaluating a Job Training Program', Review of Economic Studies, Vol.64, pp.605-654.

Ichino, A., Mealli, F. and Nannicini, T. (2008). 'From Temporary Help Jobs to Permanent Employment: What Can we Learn from Matching Estimators and their Sensitivity?', Journal of Applied Econometrics, No.23, pp.305-327.

Imbens, G.W. (2003). 'Sensitivity to Exogeneity Assumptions in Program Evaluation', AEA Papers and Proceedings, Vol.93, No.2, pp.126-132.

Lazear, E.P (2004). 'The Peter Principle: A Theory of Decline', Journal of Political Economy, Vol.112, No.1, 141-163. 
Lazaer, E.P. and Rosen, S. (1981). 'Rank-order Tournaments as Optimal Labor Contracts', Journal of Political Economy, Vol. 89, No.5, pp.841-864.

Long, S.J. and Allison, P.D. (1979). 'Entrance into the Academic Career', American Sociological Review, Vol.44, No.5, pp.816-830.

Long, S.J., Allison, P.D. and McGinnis, R. (1993). 'Rank Advancement in Academic Careers: Sex Differences and the Effects of Productivity', American Sociological Review, Vol.58, No.5, pp.703-722.

Mc Dowell, J.M., Singell, L.D. and Ziliak, J.P. (2001). 'Gender and Promotion in the Economic Profession', Industrial and Labor Relations Review, Vol.54, No.2, pp.224-244.

Milgrom, P., Roberts, J. (1992). Economics, Organization and Management, New York, Prentice Hall International.

Narcy, M. (2009). 'Would nonprofit workers accept to earn less? Evidence from France', Applied Economics, 1466-4283, First published on 12 March 2009.

Prendergast, C. (1999). 'The Provision of Incentives in Firms', Journal of Economic Literature, Vol.37, pp.7-63.

Prendergast, C. (1993). 'The Role of Promotion in Inducing Specific Human Capital Acquisition', Quarterly Journal of Economics, Vol.108, No.2, pp.523-534.

Rosenbaum, P.R. (1987). 'Sensitivity Analysis to Certain Permutation Inferences in Matched Observations', Biometrika, Vol.74, No.1, pp.13-26.

Rosenbaum, P.R. and Rubin, D.B. (1983). 'The Central Role of Propensity Score in Observational Studies for Causal Effect', Biometrika, Vol.70, pp.41-55.

Rubin, D.B. (1974). 'Estimating Causal Effects of Treatments in Randomised an Non Randomised Studies', Journal of Educational Psychology, Vol.66, pp.688-701.

Rubin, D.B. (1986). 'Comment: Which ifs have Causal Answers', Journal of the American Statistical Association, Vol.81, No.396, pp.961-962.

Schwartz, R. (2008). Commission de réflexion sur l'avenir des personnels de l'enseignement supérieur, Rapport remis à la Ministre de l'Enseignement Supérieur et de la Recherche

\section{Appendix A}

Publication score differentials before and after the "concours d'aggrégation"

\begin{tabular}{|lcccc|}
\hline Total Differential & $\begin{array}{c}(1) \\
\text { Global } \\
\text { Indicator }\end{array}$ & $\begin{array}{c}(1) \\
\text { Two-year } \\
\text { indicator }\end{array}$ & $\begin{array}{c}(1) \\
\text { Four-year } \\
\text { indicator }\end{array}$ & $\begin{array}{c}(1) \\
\text { Six-year } \\
\text { indicator }\end{array}$ \\
\hline Promoted candidates & 0.210 & 0.189 & 0.191 & 0.206 \\
\hline Full sample & $(0.179)^{\mathrm{ns}}$ & $(0.127)^{\mathrm{ns}}$ & $(0.132)^{\mathrm{ns}}$ & $(0.165)^{\mathrm{ns}}$ \\
\hline Non-promoted candidates & & & & \\
\hline Full sample & -0.229 & -0.196 & -0.204 & -0.215 \\
& $(0.101)^{* *}$ & $(0.091)^{* *}$ & $(0.099)^{* *}$ & $(0.102)^{* *}$ \\
\hline
\end{tabular}

Notes 1: Bootstrapped standard errors (obtained after 1,000 replications) are given in brackets.

Notes 2: $* * *$ : significant at $1 \%, * *$ : significant at $5 \%, *$ : significant at $10 \%$ and ns: non significant 